\title{
SUPPORTING THE THEORY ON THE POTENTIALS OF IMMOBILE RESOURCES FOR CREATING COMPETITIVE ADVANTAGES IN RURAL AREAS
}

\author{
NATASA TANDIR \\ International Burch University \\ natasa.tandir@ibu.edu.ba \\ ZAFER KONAKLI \\ International Burch University \\ zafer.konakli@ibu.edu.ba \\ SABAHUDIN BAJRAMOVIC \\ Faculty of Agricultural and Food Science \\ s.bajramovic@ppf.uns.ba
}

\begin{abstract}
For many years rural was associated with population decline, degradation of the countryside, population aging, gender inequality, increased unemployment and poverty. However, recent research emphasise that there are peripheral areas that perform good or even better than urban areas which leads to the concept of "differential performance" between rural areas which exist in relatively similar conditions related to geography, location, available natural resources, policies, etc. It is obvious that traditional theories related to rural-urban development processes, cannot explain those performance differences of rural areas with similar characteristics. In this study the authors are presenting key aspects of main development theories that can be conected to the development of rural areas. Likewise, they present the model and significant research efforts supporting the theory on the potentials of immobile resources for creating competitive advantages in rural areas and possibility for economic development (also known as Bryden's theory). In this context, immobile resources are including natural, built, human, social and cultural capital.
\end{abstract}

Keywords: rural development, theories, immobile resources

JEL classification codes: Q01, R11 